\title{
A NEW IN-VITRO MODEL TO INVESTIGATE ANTIBIOTIC PENETRATION OF THE INTERVERTEBRAL DISC
}

\author{
R. DE W. M. THOMAS, J. J. BATTEN, S. WANT, I. D. MCCARTHY, M. BROWN, S. P. F. HUGHES \\ From the Royal Postgraduate Medical School, London, England
}

We have studied the ability of a range of antibiotics to penetrate intervertebral disc tissue in vitro, using a mouse disc model. Equilibrium concentrations of antibiotics incorporated into the entire disc were determined by bioassay using a microbial growth-inhibition method.

Uptake was significantly higher with positively-charged aminoglycosides compared with negatively-charged penicillins and cephalosporins. Uncharged ciprofloxacin showed an intermediate degree of uptake.

Our results support the hypothesis that electrostatic interaction between charged antibiotics and negatively-charged glycosaminoglycans in the disc is an important factor in antibiotic penetration, and may explain their differential uptake.

J Bone Joint Surg [Br] 1995;77-B:967-70.

Received 30 January 1995; Accepted 24 March 1995

Infection of the disc space after surgery is a disabling illness with a high morbidity. It occurs in $0.75 \%$ to $4 \%$ of patients (Thibodeau 1968; Pilgaard 1969; El-Gindi et al 1976; Lindholm and Pylkkänen 1982; Staniforth et al 1984; Fernand and Lee 1986). Antibiotics have been shown experimentally to prevent infection (Fraser, Osti and Vernon-Roberts 1989) and are now used prophylactically in all branches of spinal surgery. There is still debate, however,

R. de W. M. Thomas, BSc, FRCS Ed, Orthopaedic Registrar

J. J. Batten, BSc, Research Assistant

I. D. McCarthy, PhD, Senior Lecturer

M. Brown, PhD, FRCS, Orthopaedic Registrar

S. P. F. Hughes, MS, FRCS, Professor of Orthopaedic Surgery

Department of Orthopaedics

S. Want, $\mathrm{PhD}$, Clinical Scientist

Department of Infectious Diseases

Royal Postgraduate Medical School, Hammersmith Hospital, Du Cane Road, London W12 0NN, UK.

Correspondence should be sent to Professor S. P. F. Hughes.

(C)1995 British Editorial Society of Bone and Joint Surgery 0301-620X/95/61070\$2.00 as to which antibiotics are capable of penetrating the disc to establish an effective inhibitory or therapeutic concentration (Gibson et al 1987).

The adult intervertebral disc is the largest avascular structure in the body. Nutrients and cellular metabolites enter and leave by way of passive diffusion through the adjacent bone, cartilaginous end-plates and the surrounding annulus fibrosus (Urban, Holm and Lipson 1990; Wallace et al 1994). Systemic antibiotics must also diffuse into the disc by this route.

The permeability of the disc to solutes is dependent on the sulphated glycosaminoglycan side-chains which form the aggregated proteoglycan matrix in both the annulus fibrosus and nucleus pulposus. These proteoglycans provide a high density of fixed negative charge in the matrix and also determine the matrix pore size (Urban and Maroudas 1979). Electrostatic interaction between the negatively-charged matrix and the charged solutes determines their penetration and diffusion. Thus, small neutral solutes, such as urea, have a partition coefficient of 1.0 , while small positively-charged solutes, like the mono- or divalent cations $\mathrm{Na}^{+}, \mathrm{Ca}^{2+}$ and $\mathrm{Mg}^{2+}$ have partition coefficients $>1.0$ because they are concentrated within the disc. By contrast, negatively-charged solutes such as $\mathrm{SO}_{4}{ }^{2-}$ have partition coefficients significantly $<1.0$ owing to their partial exclusion from the cartilage matrix (Maroudas 1976).

Urban et al (1990) found that negatively-charged sulphate was excluded from the nucleus pulposus while positive and uncharged solutes, such as calcium and glucose, were readily able to enter.

Substance diffusion into cartilage also depends on molecular weight (MW) and matrix pore size. Penetration decreases with increasing molecular weight. Glucose (MW 180) has a partition coefficient of 0.75 , whereas albumin (MW 67 000) has a much lower penetration of cartilage and a partition coefficient of about 0.001 (Holm 1990). This may have important clinical implications for antibiotics with a high plasma-protein-binding capacity.

Our aim was to test the hypothesis that the charge on antibiotics due to their ionisable groups is important in determining their ability to diffuse into the disc. We wished to establish an in-vitro model which would allow study of the diffusion properties of a variety of commonly used antibiotics, and to measure the effect of antibiotic charge on diffusion into the disc for a range of potentially prophylactic antibiotics. We chose to use a mouse intervertebral 
disc model as this was already available in our laboratory (Brown and Batten 1994).

\section{MATERIALS AND METHODS}

Intervertebral discs were carefully excised from the lumbar region of six-week-old male BALB/C mice (mean weight $22 \mathrm{~g}$ ). Through a dorsal incision, the lower thoracic and lumbar region was excised en bloc and the soft tissue, bony dorsal elements and corda equina removed under direct vision. Using magnification the vertebral end-plate was then carefully dissected off the vertebral body and excess bone removed, leaving the intact cartilaginous end-plate and intervertebral disc. Standard intravenous preparations of amoxycillin (Amoxil; Bencard, Brentford, UK), Augmentin (Beecham Research, Welwyn Garden City, UK), benzylpenicillin (Crystapen; Britannia Pharmaceuticals, Redhill, UK), ciprofloxacin (Ciproxin; Bayer, Newbury, UK), gentamicin (Cidomycin; Roussel, Uxbridge, UK) and tobramycin (Nebcin; Eli Lilly, Basingstoke, UK) were diluted in phosphate-buffered saline of $\mathrm{pH}$ 7.4.

Discs (nine replicates) were equilibrated overnight (16 hours) at $37^{\circ} \mathrm{C}$ in multiwell plates. Each well contained $1.0 \mathrm{ml}$ of the antibiotic solution at a concentration of

Table I. Details of the microbial inhibition bioassay

\begin{tabular}{lll}
\hline Antibiotic & Indicator organism & $\begin{array}{l}\text { Range of working } \\
\text { standards (mg/) }\end{array}$ \\
\hline Amoxycillin & Sarcina lutea & 0.006 to 1.0 \\
Benzylpenicillin & Sarcina lutea & 0.006 to 1.0 \\
Ceftriaxone & Escherichia coli & 1.5 to 250 \\
Cefuroxime & Escherichia coli & 0.6 to 10 \\
Ciprofloxacin & Escherichia coli & 0.05 to 10 \\
Clavulanic acid & Klebsiella aerogenes & 0.3 to 5.0 \\
Gentamicin & Klebsiella edwardsii & 1.0 to 16 \\
Tobramycin & Klebsiella edwardsii & 1.0 to 16 \\
\hline
\end{tabular}

$100 \mu \mathrm{m} / \mathrm{ml}$, which approaches the human peak plasma concentration for penicillins and cephalosporins used prophylactically (Bergan and Oydvin 1974; Staniforth et al 1984; Lang et al 1994).

After incubation overnight the $\mathrm{pH}$ of the solution was checked and each disc removed from the solution, blotted dry and washed free of any antibiotic on the surface by vortexing for $15 \mathrm{sec}$ in distilled water. The disc was again blotted dry, weighed accurately to $0.1 \mathrm{mg}$ and homogenised manually in $0.5 \mathrm{ml}$ of sterile water using a glass homogeniser.

A bacterial growth-inhibition bioassay was used to measure the concentration of antibiotic in the homogenised solution. A standard curve was established for each antibiotic by plotting the diameter $(\mathrm{mm})$ of the zone of inhibition (y-axis) against the antibiotic concentration $(\log g / m l)(x-$ axis).

The organisms used for assay and their sensitivity to each antibiotic tested are shown in Table I.

Zones of inhibition from the disc homogenates were used to calculate their antibiotic concentration by reference to the standard curve. The antibiotic solution remaining in the multiwell plates was also assayed to ensure that there was no loss of activity during overnight incubation.

\section{RESULTS}

The $\mathrm{pH}$ of the antibiotic solution after overnight incubation was 7.3.

Table II shows the incorporation of the antibiotics into the disc. Penetration of the disc of the positively-charged aminoglycosides, tobramycin and gentamicin, was significantly $(p<0.001)$ higher than that of the uncharged quinolone, ciprofloxacin. The negatively-charged betalactam antibiotics benzylpenicillin and amoxycillin, showed significantly poorer penetration $(\mathrm{p}<0.001)$.

The negatively-charged cephalosporins, cefuroxime and ceftriaxone, showed no measurable penetration of the disc.

Table II. Disc uptake of antibiotics ( $\mu \mathrm{m} / \mathrm{mg}$ wet weight of disc; mean \pm SD of nine replicates)

\begin{tabular}{llll}
\hline Antibiotic & Uptake & Molecular charge & MW* \\
\hline $\begin{array}{l}\text { Aminoglycosides } \\
\text { Tobramycin } \\
\text { Gentamicin }\end{array}$ & $32.71 \pm 5.31$ & Positive & 1425 \\
$\begin{array}{l}\text { Quinolone } \\
\quad \text { Ciprofloxacin }\end{array}$ & $8.57 \pm 2.03$ & Positive & \\
$\begin{array}{l}\text { Penicillins } \\
\text { Benzylpenicillin }\end{array}$ & $0.58 \pm 0.20$ & Neutral (pH 7.4) & 421 \\
$\begin{array}{l}\text { Amoxycillin } \\
\text { Amoxycillin (as Augmentin) }\end{array}$ & $0.042 \pm 0.008$ & Negative & 373 \\
Cephalosporins & $0.062 \pm 0.0007$ & Negative & 387 \\
$\quad$ Cefuroxime & Negative & 387 \\
$\quad$ Ceftriaxone & Not detected & & \\
Betalactamase inhibitors & Small zone below standard & Negative & 446 \\
$\quad$ Clavulanic acid & & & 662 \\
\hline * molecular weight & Not detected & Negative & 237 \\
\hline
\end{tabular}


Table III. Previous publications of comparable data

\begin{tabular}{|c|c|c|}
\hline Authors & Antibiotic & $\begin{array}{l}\text { Penetration of } \\
\text { nucleus pulposus }\end{array}$ \\
\hline $\begin{array}{l}\text { Aminoglycosides } \\
\text { Eismont et al (1987) } \\
\text { Currier et al (1994) }\end{array}$ & $\begin{array}{l}\text { Tobramycin } \\
\text { Gentamicin } \\
\text { Quinolone } \\
\text { Ciprofloxacin }\end{array}$ & $\begin{array}{l}\text { Yes } \\
\text { Yes } \\
\text { No published data }\end{array}$ \\
\hline $\begin{array}{l}\text { Penicillins } \\
\text { Eismont et al (1987) } \\
\text { Gibson et al (1987) } \\
\text { Riley et al (1994) }\end{array}$ & $\begin{array}{l}\text { Oxacillin } \\
\text { Flucloxacillin } \\
\text { Benzylpenicillin } \\
\text { Amoxycillin }\end{array}$ & $\begin{array}{l}\text { No } \\
\text { No } \\
\text { No } \\
\text { No published data }\end{array}$ \\
\hline $\begin{array}{l}\text { Cephalosporins } \\
\text { Lang et al (1994) } \\
\text { Gibson et al (1987) } \\
\text { Eismont et al (1987) } \\
\text { Fraser et al (1989) }\end{array}$ & $\begin{array}{l}\text { Cefuroxime } \\
\text { Ceftriaxone } \\
\text { Cephradine } \\
\text { Cephalothin } \\
\text { Cephazolin }\end{array}$ & $\begin{array}{l}\text { No published data } \\
\text { Yes } \\
\text { No } \\
\text { No } \\
\text { No }\end{array}$ \\
\hline
\end{tabular}

Small inhibitory zones were seen with ceftriaxone, but these were below the limits of detection for the assay. The betalactamase inhibitor component of Augmentin, clavulanic acid, also failed to penetrate the disc.

\section{DISCUSSION}

We describe an in vitro mouse model using an intact intervertebral disc for the study of antibiotic penetration. Previous studies have been carried out in vivo using animal models (Eismont et al 1987; Fraser et al 1989; Scuderi et al 1993; Currier, Banovac and Eismont 1994) and patients (Gibson et al 1987; Lang et al 1994). Although useful in assessing the potential prophylactic value of an antibiotic they introduce other pharmacokinetic variables which are independent of the physicochemical properties of the drug. This makes it difficult to identify and evaluate the factors which actually determine the ability of the antibiotic to penetrate the disc.

Recently, Riley et al (1994) described the penetration of the intervertebral disc by gentamicin and penicillin in a rabbit model and concluded that the charge effect influenced their penetration and distribution.

In vitro studies allow us to identify individual factors responsible for antibiotic diffusion into the disc. Knowledge of these may be important in the selection of an antibiotic for effective prophylactic use. With our model more than 30 discs can be easily harvested from mice in one session allowing several antibiotics to be investigated together.

The markedly greater degree of penetration of disc tissue by the positively-charged aminoglycoside antibiotics, compared with the negatively-charged penicillins and cephalosporins, supports the hypothesis that the charge due to ionisable groups on the antibiotic molecule is an important factor in determining the ability to diffuse into the intervertebral disc. We equilibrated the discs with antibiotic solution at peak plasma concentration, and our results probably represent the upper limit for uptake. Equilibration rates are relatively slow in human discs and if plasma clearance times are a significant proportion of the equilibration time then uptake into the disc will be reduced. Significant plasma-protein binding, as seen with some antibiotics, will also inhibit uptake.

Our results are consistent with previous studies carried out in vivo (Table III). Aminoglycosides have been found to penetrate the nucleus in rabbits (Eismont et al 1987; Currier et al 1994; Riley et al 1994), whereas the firstgeneration cephalosporins, cephradine and cephazolin, showed no evidence of penetration in patients (Gibson et al 1987) or in a sheep model (Fraser et al 1989).

The latter group found that in four out of five discs cephazolin was present only in the annulus fibrosus and suggested that antibiotic penetration of the normal intervertebral disc occurred through the outer annulus fibrosus and not by the central end-plates. Because of the small size of the mouse disc we were unable to differentiate between the nucleus and annulus, but this explanation may account for the accumulation of the positively-charged aminoglycosides within the nucleus pulposus at steady state, as occurs with other cations such as calcium (Urban 1990), with the negatively-charged betalactams penetrating only the annulus fibrosis. Ciprofloxacin has positively-charged ionisable groups at a lower $\mathrm{pH}$ such as occurs within the anaerobic disc (Holm 1990).

High-molecular-weight proteins such as albumin have a low partition coefficient. Some of the cephalosporin and penicillin groups have a high plasma-protein-binding capacity (60\% to $85 \%)$ compared with gentamicin ( $20 \%$ to $30 \%$ ) and this will inhibit uptake into the disc.

The newer, third-generation ceftriaxone has been shown, using gas-liquid chromatography, to penetrate the human disc (Lang et al 1994). Although we did find small zones of inhibition in the discs equilibrated with ceftriaxone, these were too low to quantitate by the less sensitive bioassay technique.

We have shown that the mouse disc model demonstrates comparable antibiotic penetration of intervertebral discs as in previous studies in vivo. There is a significant and marked increase in penetration with the positively-charged aminoglycosides, gentamicin and tobramycin, compared with penicillins and cephalosporins, suggesting that antibiotic charge is the principal factor influencing uptake into the disc. The aminoglycosides may be a better choice of antibiotic for prophylactic use in spinal surgery.

No benefits in any form have been received or will be received from a commercial party related directly or indirectly to the subject of this article.

\section{REFERENCES}

Bergan T, Oydvin B. Cross-over study of penicillin pharmacokinetics after intravenous infusions. Chemotherapy 1974;20:263-79.

Brown MF, Batten JJ. Organ culture of whole intervertebral discs: a new technique. J Bone Joint Surg [Br] 1994;76-B:Suppl II, 90.

Currier LC, Banovac K, Eismont FJ. Gentamicin penetration into normal rabbit nucleus pulposus. Spine 1994;19:2614-8. 
Eismont FJ, Wiesel SW, Brighton CT, Rothman RH. Antibiotic penetration into rabbit nucleus pulposus. Spine 1987;12:254-6.

El-Gindi S, Aref S, Salama M, Andrew J. Infection of intervertebral discs after operation. J Bone Joint Surg [Br] 1976;58-B:114-6.

Fernand R, Lee CK. Postlaminectomy disc space infection: a review of the literature and a report of three cases. Clin Orthop 1986;209:215-8.

Fraser RD, Osti OL, Vernon-Roberts B. Iatrogenic discitis: the role of intravenous antibiotics in prevention and treatment: an experimental study. Spine 1989;14:1025-32.

Gibson MJ, Karpinski MRK, Slack RCB, Cowlishaw WA, Webb JK. The penetration of antibiotics into the normal intervertebral disc. $J$ Bone Joint Surg [Br] 1987;69-B:784-6.

Holm SH. Nutrition of the intervertebral disc. In: Weinstein JN, Wiesel SW, eds. The lumbar spine. W. B. Saunders Company, 1990:244-60.

Lang R, Folman Y, Ravid H, Bental T, Gepstein R. Penetration of ceftriaxone into the intervertebral disc. J Bone Joint Surg [Am] 1994;76-A:689-91.

Lindholm TS, Pylkkänen P. Discitis following removal of intervertebral disc. Spine 1982;7:618-22.
Maroudas A. Transport of solutes through cartilage: permeability to large molecules. J Anat 1976;122:335-47.

Pilgaard S. Discitis (closed space infection) following removal of lumbar intervertebral disc. J Bone Joint Surg [Am] 1969;51-A:713-6.

Riley LH, Banovac K, Martinez OV, Eismont FJ. Tissue distribution of antibiotics in the intervertebral disc. Spine 1994;19:2619-25.

Scuderi GJ, Greenberg SS, Banovac K, Martinez OV, Eismont FJ. Penetration of glycopeptide antibiotics in nucleus pulposus. Spine 1993; 18:2039-42.

Staniforth DH, Jackson D, Horton R, Davies B. Parenteral augmentin: pharmacokinetics. Int J Clin Pharmcol Ther Toxicol 1984;22:430-4.

Thibodeau AA. Closed space infection following removal of lumbar intervertebral discs. J Bone Joint Surg [Am] 1968;50-A:400-10.

Urban J, Holm SH, Lipson SJ. Disc biochemistry in relation to function. In: Weinstein JN, Wiesel SW, eds. The lumbar spine. W. B. Saunders Company, 1990:231-43.

Urban JP, Maroudas A. Measurement of fixed charge density in the intervertebral disc. Biochem Biophys Acta 1979;586:166-79.

Wallace AL, Wyatt BC, McCarthy ID, Hughes SP. Humoral regulation of blood flow in the vertebral endplate. Spine 1994;19:1324-8. 